\title{
Sludge drying leads to organic nitrogen mineralization
}

\author{
Lukasz Kokurewicz ${ }^{1}$, Kamil Janiak ${ }^{1,}$, and Bartosz Zięba ${ }^{1}$ \\ ${ }^{1}$ Faculty of Environmental Engineering, Wroclaw University of Science and Technology, \\ Plac Grunwaldzki 9, 50-377 Wroclaw, Poland
}

\begin{abstract}
Sludge drying leads to volatisation and removal of part of nitrogen contained in sludge. Removed nitrogen is usually condensed and recirculated to activated sludge process. It is assumed that mass of volatised nitrogen is equal to mass of soluble nitrogen in sludge. However results obtained from full-scale drying facility shows that mass of volatised nitrogen is $100 \%$ higher than mass of soluble nitrogen. It is suspected that nitrogen mineralization occurs due to high temperature maintained in dryers $\left(>220^{\circ} \mathrm{C}\right)$. These results are important as higher mass of nitrogen in condensate makes its removal economically reasonable. This paper shows results of nitrogen mass balance of full-scale drying facility.
\end{abstract}

\section{Introduction}

It is anticipated that in 2018 nearly 710000 tons of dry sludge mass will be produced in Poland [1]. In 2013 only 13\% of sludge was thermally transformed [1] by 29 drying facilities (12 solar and 17 mechanical) [2]. Additional 10 mechanical dryers were under construction [2]. Fraction of sludge that is thermally transformed will increase in the future, and new facilities will be commissioned. Therefore sludge drying will be common technology in larger wastewater treatment plants.

Water removed from sludge during drying (condensate) contains nitrogen in form of ammonium [3]. Condensate is recirculated to activated sludge process for nitrification. It is assumed that drying leads to removal of only soluble nitrogen from sludge and organic nitrogen remaining intact $[3,4]$. As most of soluble nitrogen is removed from sludge during dewatering, mass of nitrogen in condensate from drying is considered low. It is however possible that some part of organic nitrogen could be mineralized in full scale mechanical dryers which are exploited at higher temperatures than dryers used in laboratory studies $[3,4]$.

M. Horttanainen [3] and K. Mustonen [4] showed interesting results on nitrogen flows in lab-scale dryers fed with municipal sludge and sludge from paper industry. Tests were conducted in different drying temperatures. Obtained results showed that only soluble nitrogen is removed from sludge during drying and mass of nitrogen in fumes is ca $10 \%$ of nitrogen in raw sludge. S. A. O'Shaughnessy [5] presented results on nitrogen loss during solar drying. Most of nitrogen lost during drying was soluble nitrogen in evaporated

\footnotetext{
*Corresponding author: janiakkamil@gmail.com
} 
water. Wang Y. et al. [6] and B. Karwowska et al. [7] published data on condensate parameters from overall 3 full scale drying facilities. Their results shows that nitrogen concentrations in condensate can exceed $500 \mathrm{~g} \mathrm{~N} / \mathrm{m}^{3}$. However no data about nitrogen loads were presented.

Therefore little is known about nitrogen flows during drying as only few papers are available. If substantial mineralization of organic nitrogen occurs in full scale dryers it will lead to additional mass of nitrogen recirculated. This is important information as it may make treatment of sludge drying condensate feasible as well as indicate that nitrogen from sludge drying facilities should be included in design process of activated sludge reactors (which is not at this moment).

\subsection{Aim of paper}

Aim of this paper is to show evidence that substantial mineralization of organic nitrogen may occur in sludge drying facilities. Thesis of nitrogen mineralization is confirmed by measurements made in a full-scale sludge drying facility in Poland.

\section{Materials and methods}

Fermented sludge is delivered to dewatering by means of filter presses from which samples were taken directly. Then it is collected in storage tanks and then fed into a drying line, where condensate is released during the process. The dried sludge is collected in a bulk silo, which was the second sampling site. The installation is shown in Figure No. 1.
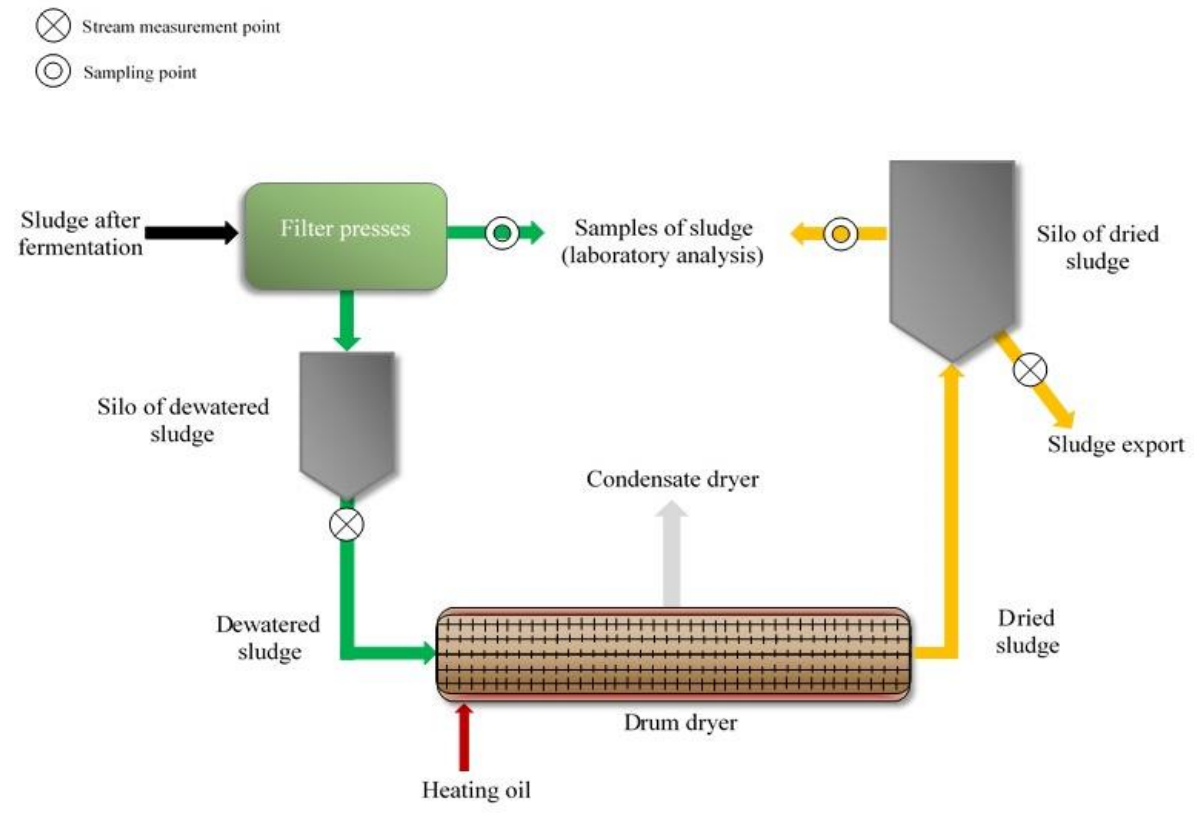

Fig. 1. Sludge drying system.

Samples of dewatered and dried sludge were analyzed for dry matter and total nitrogen content. Additionally, the content of ammonium nitrogen in the effluents after filter presses was measured and the concentration of total Kjeldahl nitrogen was estimated on the basis of the ratio between ammonium nitrogen and total nitrogen, based on historical data. 
Dewatered sludge stream as well as dried sludge stream were determined based on the IT data from SCADA system. Condensate stream was determined as the difference between two streams mentioned in previous sentence. The measurement methods are summarized in Table No. 1.

Table 1. Analysis and calculation methods.

\begin{tabular}{|c|c|c|c|c|}
\hline Stream type & $\begin{array}{c}\begin{array}{c}\text { Number } \\
\text { of } \\
\text { analyzes }\end{array} \\
\end{array}$ & $\begin{array}{c}\text { Type of } \\
\text { laboratory } \\
\text { analysis } \\
\end{array}$ & $\begin{array}{c}\text { Methodology of laboratory } \\
\text { analysis }\end{array}$ & $\begin{array}{c}\text { Method for } \\
\text { determining the } \\
\text { mass stream }\end{array}$ \\
\hline $\begin{array}{l}\text { Dewatered } \\
\text { sludge }\end{array}$ & $\begin{array}{l}38 \\
18\end{array}$ & $\begin{array}{l}\text { Dry mass } \\
\begin{array}{c}\text { Total Kjeldahl } \\
\text { nitrogen }\end{array} \\
\end{array}$ & $\begin{array}{l}\text { PN-EN 12880:2004 } \\
\text { PN-EN 13342:2002 }\end{array}$ & $\begin{array}{l}\text { Weight in silo of } \\
\text { dewatered sludge }\end{array}$ \\
\hline Dried sludge & 38 & $\begin{array}{c}\text { Dry mass } \\
\begin{array}{c}\text { Total Kjeldahl } \\
\text { nitrogen }\end{array} \\
\end{array}$ & $\begin{array}{l}\text { PN-EN 12880:2004 } \\
\text { PN-EN 13342:2002 }\end{array}$ & $\begin{array}{l}\text { Weight of dried } \\
\text { sludge exported to } \\
\text { other companies }\end{array}$ \\
\hline Condensate & 20 & $\begin{array}{l}\text { Ammonium } \\
\text { nitrogen } \\
\text { Total Kjeldahl } \\
\text { nitrogen }\end{array}$ & $\begin{array}{l}\text { Hach Lange's photometric } \\
\text { tests LCK303 } \\
\text { The proportion of ammonium } \\
\text { nitrogen }\end{array}$ & $\begin{array}{l}\text { The difference } \\
\text { between dewatered } \\
\text { and dried sludge }\end{array}$ \\
\hline
\end{tabular}

\section{Results}

\subsection{Theoretical nitrogen load in condensate}

In the case of condensate it is assumed that the characteristics of the condensate stream generated during the drying process should not differ from the dewatering liquid. Therefore nitrogen load in condensate can be estimated on basis of nitrogen content in dewatering liquid and mass of water removed during drying. The obtained data are presented in Figure No. 2.

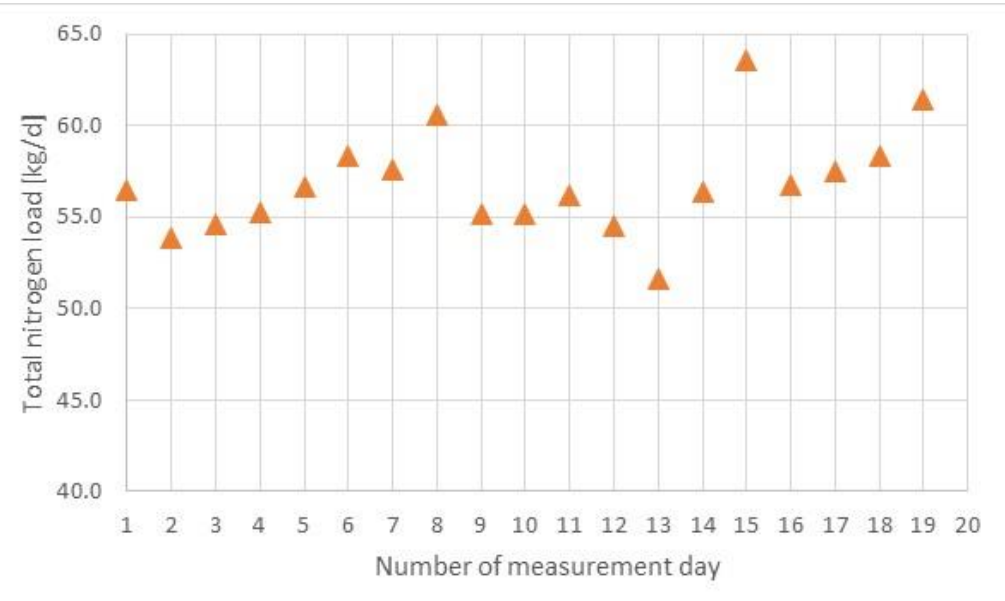

Fig. 2. Total nitrogen load in the condensate. 
Average theoretical nitrogen load in condensate is presented in Table No. 2.

\subsection{Analysis of sludge}

Nitrogen load in released condensate may also be calculated on basis of difference in nitrogen load between dewatered and dried sludge. The results on total nitrogen concentration in dewatered as well as dried sludge are presented in Figure No. 3.

The average dry matter content of $21.5 \%$ occurred in the case of dewatered sludge, while the total nitrogen content was $4.92 \%$ of dry matter. In the case of dried sludge, these values oscillated at $93.5 \%$ and $4.55 \%$ of dry matter, respectively. The monthly average flow determined on the basis of data collected by the SCADA system was $94.6 \mathrm{t} / \mathrm{d}$ for dewatered sludge and $20.9 \mathrm{t} / \mathrm{d}$ for dried sludge. The retention time of the sludge drying unit was the same and was 3 minutes for each sample. Data fluctuations may result from measurement uncertainty of dry matter of $10 \%$ of the value (according to the methodology from Table 1).

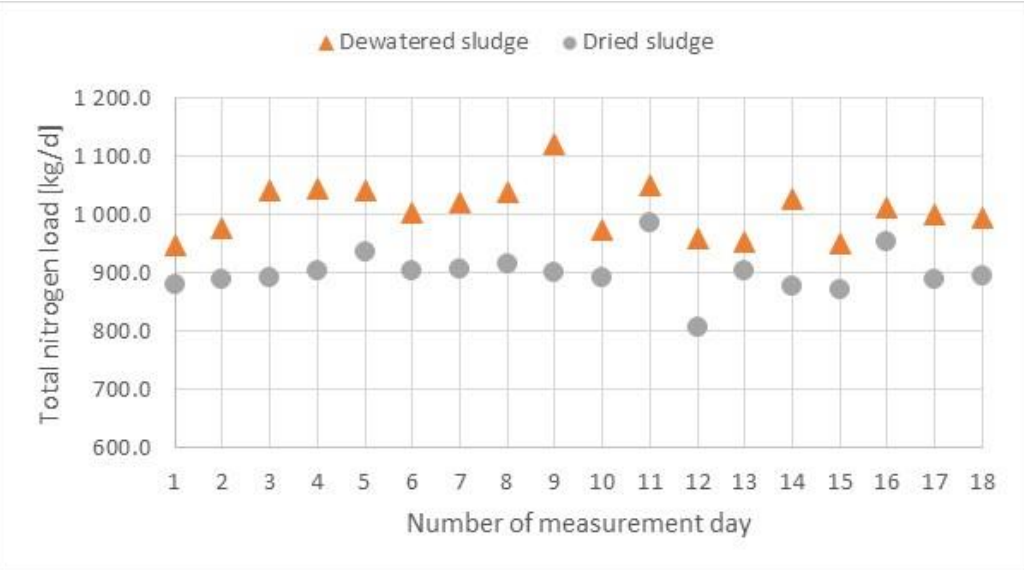

Fig. 3. The nitrogen content in sludge.

The concentration of total Kjeldahl nitrogen in the condensate was determined on the basis of the ratio between ammonium nitrogen and total nitrogen in the effluents after filter presses on the same object (see Table No. 1, Chapter 2 and Chapter 3.1).

The results of calculations of loads are presented in Table No. 2.

Table 2. Calculation of nitrogen mass balance.

\begin{tabular}{|l|c|c|c|c|c|}
\hline Stream type & $\begin{array}{c}\text { Mass } \\
\text { stream }\end{array}$ & $\begin{array}{c}\text { Nitrogen } \\
\text { concentration }\end{array}$ & $\begin{array}{c}\text { Average dry } \\
\text { matter }\end{array}$ & \multicolumn{2}{|c|}{ Total nitrogen load (average) } \\
\hline $\begin{array}{c}\text { Dewatered } \\
\text { sludge }\end{array}$ & $94.6 \mathrm{t} / \mathrm{d}$ & $4.9 \begin{array}{c}\% \text { of dry } \\
\text { matter }\end{array}$ & $21.5 \%$ & $0.995 \mathrm{t} \mathrm{N} / \mathrm{d}$ & $995 \mathrm{~kg} \mathrm{~N} / \mathrm{d}$ \\
\hline Dried sludge & $20.9 \mathrm{t} / \mathrm{d}$ & $4.5 \begin{array}{c}\% \text { of dry } \\
\text { matter }\end{array}$ & $93.5 \%$ & $0.879 \mathrm{t} \mathrm{N} / \mathrm{d}$ & $879 \mathrm{~kg} \mathrm{~N} / \mathrm{d}$ \\
\hline $\begin{array}{c}\text { Condensate } \\
\text { (theoretical) }\end{array}$ & $73.7 \mathrm{t} / \mathrm{d}$ & $765.8 \mathrm{~g} \mathrm{~N} / \mathrm{m}^{3}$ & - & $0.056 \mathrm{t} \mathrm{N} / \mathrm{d}$ & $56 \mathrm{~kg} \mathrm{~N} / \mathrm{d}$ \\
\hline
\end{tabular}




\subsection{Nitrogen mass balance of sludge dewatered and dried}

On the basis of the data from Table No. 2, the balance of streams shown in Figure 4 was made.

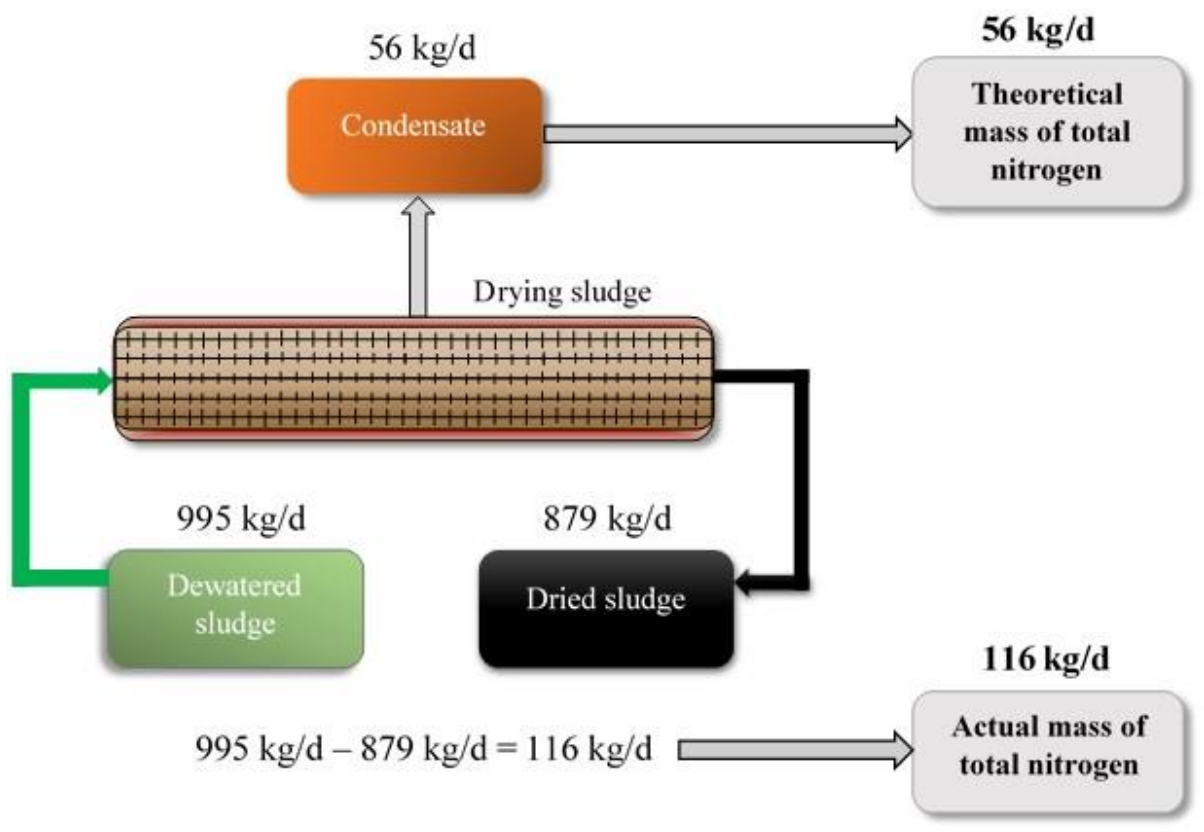

Fig. 4. The balance of total nitrogen in the analyzed streams.

The nitrogen mass resulting from the difference of sludge streams (dewatered and dried) is $116 \mathrm{~kg} \mathrm{~N} / \mathrm{d}$. While theoretical value is considerably lower $(56 \mathrm{~kg} \mathrm{~N} / \mathrm{d})$.

\section{Conclusions}

Main conclusions are:

1. Mass of nitrogen in condensate is considerably higher than mass estimated on basis of soluble nitrogen content in dewatered sludge before drying.

2. Mineralization of part of organic nitrogen may occur in dryer due to high sustained temperature.

3. As knowledge about nitrogen flows in dryers is scarce, more research is needed to confirm presented results.

The authors gratefully acknowledge co-funding from the National Centre for Research and Development (grant no LIDER/16/0172/L-7/15/NCBR/2016). Authors would also thank Municipal Water and Sewage Company in Wroclaw for financial support as well as for access to sludge drying facility. 


\section{References}

1. S. Werle, Ecol. Chem. Eng. 22(3), 459-469 (2015)

2. J. Niesler, J. Nadziakiewicz, Industrial Furnaces \& Boilers. 9-10, 29-41 (2013) www.infona.pl/resource/bwmeta1.element.baztech-6a7a3ed7-7f79-460c-afb3-78b eced5cf68

3. M. Horttanainen, I. Deviatkin, J. Havukainen, Journal of Cleaner Production 142, 1819-1826 (2017)

4. K. Mustonen, I. Deviatkin, J. Havukainen, M. Horttanainen, Environmental Technology 29, 1-9 (2017)

5. S. A. O’Shaughnessy, I. Song, J. F. Artiola, C. Y. Choi, Environmental Technology 29, 55-65 (2008)

6. Y. Wang, F. Wang, M. Ji, Advanced Materials Research 777, 127-132 (2013)

7. B. Karwowska, E. Sperczynska, E. Wisniowska, Desalination and water treatment, 57, 1176-1183 (2016) 